\title{
The effects of tricyanoaminopropene on learning in a differential reinforcement of low rates situation*
}

\author{
DAVID L. MORSE and PAUL R. SOLOMON \\ State University College, New Paltz, N.Y. 12561
}

Thirty male Wistar rats were assigned randomly to one of six groups $(6,12$, or $24 \mathrm{mg} / \mathrm{kg}$ of TRIAP, .2 or $.8 \mathrm{mg} / \mathrm{kg}$ of d-amphetamine, or a control group receiving $.3 \%$ tragacanth). All Ss were trained on a DRL 5- and DRL 10-sec schedule of reinforcement. With the DRL 10-sec schedule it was found that the animals injected with TRIAP reached the criterion for learning in significantly fewer trials than did the d-amphetamine and control groups. This suggests that the beneficial effects of TRIAP are due to a learning rather than a stimulant effect.

Recent studies dealing with the effect of the drug tricyanoaminopropene (TRIAP) on learning have produced conflicting results. Brush, Davenport, \& Polidora (1966) were unable to demonstrate that TRIAP enhanced the acquisition and retention of a shuttlebox avoidance task, and Gurowitz, Gross, \& George (see Gurowitz, 1969) found a single dose of TRIAP to be detrimental to passive-avoidance learning. Other studies, however, have reported more positive results with TRIAP. Chamberlin, Rothschild, \& Gerard (1963) found that the drug facilitated avoidance conditioning in rats, while Solyom \& Gallay (1966) showed that TRIAP enhanced barpress acquisition with a variable-interval schedule of reinforcement.

The purpose of this study is to determine if TRIAP actually enhances learning or merely acts as a stimulant and therefore facilitates performance. The experiment will employ a differential-reinforcement-of-low-rates (DRL) schedule of reinforcement in which the Ss must learn to delay the response to receive the reinforcement. In this situation, increased motor activity should hinder acquisition and if TRIAP acts as a stimulant it should retard leaming. If, however, the drug enhances a central associative mechanism, the TRIAP-treated animals should show faster acquisition on the DRL schedule than either the control animals or ones treated with d-amphetamine, a central-nervous-system stimulant.

\section{APPARATUS}

The apparatus for this experiment consisted of three Grason-Stadler Model E3125AA-3 test chambers, each containing a standard one-bar Skinner box. All programming was done with the

*This research was supported in part by Grant 26-7119A from the State of New York Research Foundation.
Grason-Stadler Model E6186 relay rack. Noyes food pellets weighing $35 \mathrm{mg}$ each were used as reinforcement.

\section{SUBJECTS}

The Ss used in this study were 30 male albino rats from the Wistar strain, approximately 100 days old and weighing between 170 and $200 \mathrm{~g}$ at the beginning of the experiment. During the experiment, and for the week prior to it, the Ss were placed on a 23-h food-deprivation schedule. Water was available ad lib except during testing.

\section{PROCEDURE}

The Ss were initially trained to barpress on a continuous reinforcement schedule, and then were given two additional sessions on CRF until satiation. The $30 \mathrm{Ss}$ were then assigned randomly to one of six groups, five Ss per group. The five experimental groups were given 6,12 , or $24 \mathrm{mg} / \mathrm{kg}$ of TRIAP, or .2 or $.8 \mathrm{mg} / \mathrm{kg}$ of d-amphetamine, the TRIAP and $\mathrm{d}$-amphetamine being suspended in a $.3 \%$ tragacanth solution. The sixth group of Ss received a control injection of .3\% tragacanth.

Prior to this experiment, a pilot study was conducted to determine if the $.8 \mathrm{mg} / \mathrm{kg}$ dose of d-amphetamine hindered consummatory behavior. Twelve male albino rats on a 23-h deprivation schedule were injected i.p. with either $.3 \%$ tragacanth or $.8 \mathrm{mg} / \mathrm{kg}$ d-amphetamine, and $30 \mathrm{~min}$ later these animals were given food ad lib for $1 \mathrm{~h}$. There was no significant difference between the two groups in amount of food consumed $(\mathrm{t}=1.75, \mathrm{df}=10, \mathrm{p}>.10)$.

Four days after initial barpress training, the 30 experimental Ss were given i.p. injections of the appropriate drug, and $30 \mathrm{~min}$ later were placed into a Skinner box for DRL training. During the first schedule of reinforcement (DRL $5 \mathrm{sec}$ ) $\mathrm{S}$ could gain reinforcement only by a barpress that followed the previous one by a time interval of $5 \mathrm{sec}$ or longer. Any barpress response that occurred in a time span shorter than $5 \mathrm{sec}$ reset a timer, and $\mathrm{S}$ was again required to withhold the response before reinforcement would be available. The barpress responses were broken up into blocks of 10 responses each. The criterion for learning under the DRL $5 \mathrm{sec}$ was six reinforced responses in a block of 10 responses, the Ss remaining on this schedule until they met this criterion.

Two days after the animals had acquired the DRL 5-sec schedule, they were placed on a DRL $10-\sec$ schedule, and $1 / 2 \mathrm{~h}$ prior to this they received an i.p. injection of the same drug treatment that preceded the DRL-5 acquisition. During DRL 10-sec acquisition a response was reinforced only if the interresponse interval was 10 or more seconds. As in the previous DRL schedule, the criterion for learning was six reinforced responses in a block of 10 responses. The dependent variable was the number of blocks of trials to reach the criterion on the two DRL schedules.

\section{RESULTS}

An analysis of variance on the number of blocks of trials to reach the criterion for learning on the DRL S- and DRL 10-sec schedules demonstrated a significant interaction between the schedule of reinforcement and the drug treatment $(\mathrm{F}=3.46, \quad \mathrm{df}=5,24, \quad \mathrm{p}<.05) . \quad \mathrm{A}$ breakdown of the Drug by Schedule interaction into simple effects showed that there was no significant difference between the various drugs with the DRL 5-sec schedule of reinforcement. The overall $F$ test on the drug effects with the DRL 10-sec schedule was significant $(F=8.68, d f=5,24, p<.01)$.

A Duncan range test based upon trials to criterion with the DRL 10-sec schedule indicated significant differences between each of the TRIAP groups $(6,12$, and $24 \mathrm{mg} / \mathrm{kg}$ ) and the $.8 \mathrm{mg} / \mathrm{kg}$ d-amphetamine group. In addition, significant differences were found between the two higher doses of TRIAP and the . $3 \%$ tragacanth control group as well as between the $24 \mathrm{mg} / \mathrm{kg}$ TRIAP group and the $.2 \mathrm{mg} / \mathrm{kg}$ d-amphetamine group. No significant differences were found between the three different doses of TRIAP. Figure 1 shows the mean number of trial blocks for each group to reach the criterion at the DRL 10-sec schedule of reinforcement.

\section{DISCUSSION}

In contrast with previous work examining similar behavioral processes (Gurowitz, 1969; Brush et al, 1966), the data from this study indicates that the drug tricyanoaminopropene has beneficial effects on learning. These beneficial effects were present only at the DRL 10-sec 


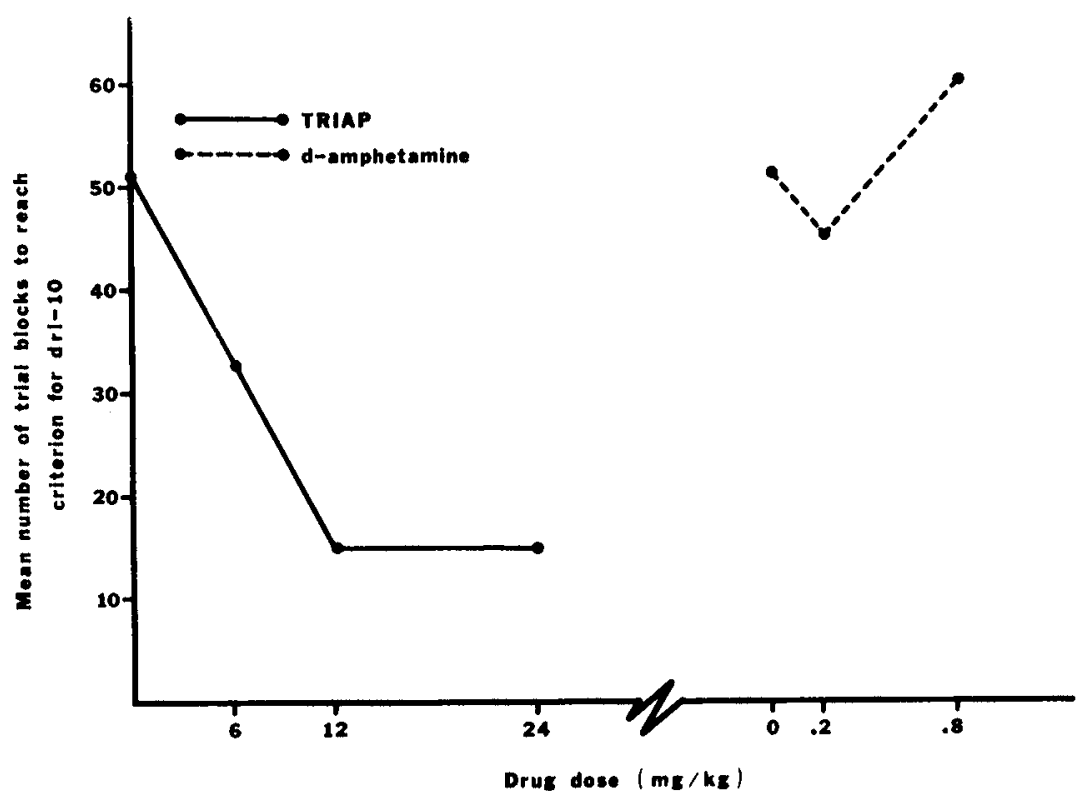

schedule and the lack of significant differences at the DRL-5 schedule seem to be more readily explained on the basis of experimental design than on effects of the drug. The consummatory behavior involved in eating the reinforcement required a good part of the time necessary to withhold the barpress response in order to gain the next reinforcement, and it is entirely possible that the DRL-5 schedule of reinforcement is too short an interval to assess correctly the effects of the drug. As the dose of TRIAP increased the number of blocks of trials to reach criterion on the DRL 10-sec drug doses did not differ enough. performance.
Fig. 1. The mean number of blocks of trials to reach the criterion on the DRL 10-sec schedule of reinforcement as a function of TRIAP and d-amphetamine. For clarity of comparison, the .3\% tragacanth control group is plotted as zero amount of both drugs.

d-amphetamine groups in this experiment were intended to demonstrate that a drug that has the property of being a central-nervous-system stimulant will have detrimental effects on learning in a DRL situation. While in all cases, with the exception of the $.2 \mathrm{mg} / \mathrm{kg}$ d-amphetamine group at the DRL 10-sec schedule, the amphetamine groups took more trials to reach the criterion than the control group, and furthermore in all cases the higher-amphetamine group took more trials than the lower-dose group, no significant differences were found between the means. Once again this may be due to too small a difference between the drug doses.

schedule decreased. The differences among the means of the TRIAP groups, however, were not significant, perhaps because the

Possibly the most important finding of this study was that all TRIAP groups, with the exception of the $6 \mathrm{mg} / \mathrm{kg}$ TRIAP dose did significantly better than the control or either of the d-amphetamine groups. This supports the hypothesis that the beneficial effect of TRIAP is actually due to an enhancement in learning rather than

It should be noted that the
REFERENCES

BRUSH, F., DAVENPORT, J., \& POLIDORA, V TCAP: Negative results in avoidance and water maze learning and retention. Psychonomic Science, 1966, 4, 183-184.

CHAMBERLIN, T., ROTHSCHILD, G., \& GERARD, R. Drugs affecting RNA and learning. Proceedings of the National Academy of Science, 1963, 49, 918-924.

GUROWTTZ, E. The molecular basis of memory. Englewood Cliffs, N.J: Prentice-Hall, 1969.

SOLYOM, L., \& GALLEY, H. Effect of malononitrile dimer on operant and classical conditioning of aged white rats. International Journal of Neuropsychiatry, 1966, 2, 577-584. 